\title{
A case of bilateral temporal lobe agenesis
}

\author{
C L A N G, S LEHRL, A N D H U K \\ From the Department of Neurology, Psychiatry, and Neurosurgery, University of Erlangen-Nürnberg, \\ West Germany
}

SUMMARY A 76-year-old man with bilateral temporal lobe agenesis producing clinical features resembling the Robinson syndrome is described. The malformation was discovered during a routine CT examination after the appearance of a homonymous visual field defect. The patient was examined by (neuro) psychological testing. The findings are compared with other reported cases and discussed with regard to cerebral localisation.

Isolated cerebral lobe agenesis unassociated with defects of other structures and without apparent functional disorders were usually not detected in life before the introduction of cranial computed tomography (CT).

On the basis of 10 cases Robinson ${ }^{1}$ established the so-called "temporal lobe agenesis syndrome" as a clinical entity. These cases were distinguished by a defect on one side and discovered on the occasion of a thorough medical examination. The syndrome was "four times commoner in the male than the female. Most patients present clinically between five and 21 years of age but incidental cases have been found at autopsy up to 74 years of age. Headache is the leading symptom and in some the temporal bulging had been apparent to the parents soon after birth. Usually neurological signs are minimal or absent and there may be a generalised prominence of the temporal area of the skull. In a few patients the headaches are severe, and papilloedema and a mild hemiparesis are found. The lesions are commoner on the left with a left/right ratio of $3: 2 .{ }^{2}$ Radiological signs are an elevation of the lesser wing of the sphenoid bone and the middle cerebral artery in anterior-posterior projection. Other authors add a facial asymmetry and slight exophthalmos of the side concerned. The ventricles of the side involved are usually small. Seur and Kooman ${ }^{3}$ mention a hyperplasia of the sphenoid sinus (pneumosinus dilatans) as a prominent sign on plain skull radiographs. Other terms for this syndrome are

Address for reprint requests: Dr C Lang, Universitäts- Niewenklinik, Schwabachanlage 6, 8520 Erlangen, West Germany.

Accepted 18 May 1981 "cerebral arachnoid cyst," "subarachnoid cyst" and "subarachnoid pouch." Reports before 1955, the time when Robinson first described the syndrome, classify it under "porencephaly," "pseudoporencephaly," or "cystic hygroma."4

Further case reports after Robinson who by 1968 had added 10 more descriptions to the 18 already known in publications were given by Aguilera, Blázques and Obrador ${ }^{5}$ who reported on three cases, and by Seur and Kooman ${ }^{3}$ who contributed another two cases. The latter authors presented two male patients aged 15 and 19 years without neurological deficit who supposedly originally had a temporal lobe agenesis leading to secondary manifestations in the form of a bulging of the temporal squamae, excessive pneumatisation of the sphenoid sinus, and an abnormal course of the intracerebral blood vessels. Kolberg ${ }^{6}$ who published five additional personal observations of patients between two-and-a-half and 57 years of age assumed a developmental disorder with compression of the vein of Rosenthal through strangulation of the hippocampus in the tentorial hiatus as the underlying disorder. Kolberg regarded the temporal lobe agenesis as a porencephaly and therefore as secondary, so he proposed the name "incisural porencephaly of the temporal lobe." Without anticipating any specific pathogenesis we will refer to "temporal lobe agenesis."

There are several examples of one-sided temporal lobe agenesis revealed by CT: without further description Shields, Isherwood and Pullan ${ }^{7}$ presented a transverse axial tomogram of a left-sided arachnoidal cyst covering the area of the left temporal lobe. The 22-year-old male patient of New and $\operatorname{Scott}^{8}$ suffering from headaches of 
several months duration had "a large, well-defined, cavitary-appearing lesion . . . in the right frontotemporal region with an absorption range of 618 units. . . Considering the size of this lesion, there [was] a rather modest mass effect upon the ventricular system (suggesting an underlying loss of cerebral substance)." Lange, Grumme and Meese $^{9}$ presented the tomogram of a one-year-old child whose left temporal region was filled by CSF.

As far as we know, only three cases of bilateral temporal lobe agenesis have been reported, none of them shown by CT. The first is that described by Faris $^{10}$ who found in a 41-year-old woman suffering from a psychiatric illness an unusual bitemporal bulging and thinning of the squamae, an elevation of the lesser sphenoid wing on both sides, marked dilatation of the third and lateral ventricles, and an abnormal course of the middle cerebral arteries, which may be described as a bilateral form of the Robinson's syndrome. The second case is that of Tuynman, Hekster and Pauwels ${ }^{11}$ who reported on a 14-month-old girl with bilateral temporal arachnoid cysts who was found to be blind. Again the plain skull radiographs indicated a bilateral expanding lesion and arteriography showed the typical upward course of both middle cerebral arteries. Routine Tcscintigram demonstrated a pathological accumulation of radionuclide on the right side only. Shaw and Alvord ${ }^{12}$ among 5000 necropsy specimens mention a case of bilateral temporal arachnoid cysts without further comment.

We present a patient with bilateral temporal lobe agenesis who not only was examined by CT but also from psychological and neuropsychological aspects.

\section{Case report}

The patient is a 76-year-old business man who is now retired but is still active on a voluntary basis. After training in electrical engineering and mechanics he underwent commercial apprenticeship and became a state official before he decided to become selfemployed. Besides philately, hiking in the mountains, sailing and motor-cycling his hobbies comprised active music making on at least five musical instruments. He had been fully employed up to the age of 75 years.

\section{Neuro-ophthalmological findings}

Nine weeks before we examined the patient, he complained of visual disturbance and a homonymous field defect was discovered by perimetry (fig 1). Arteriosclerotic retinopathy and arterial hypertension were present, which led to the assumption that there was a vascular disorder. Slow filling of the retinal vessels was detected by fluorescence angiography, but as the patient objected to a carotid arteriography, the suspected stenosis of the right carotid artery could not be demonstrated.

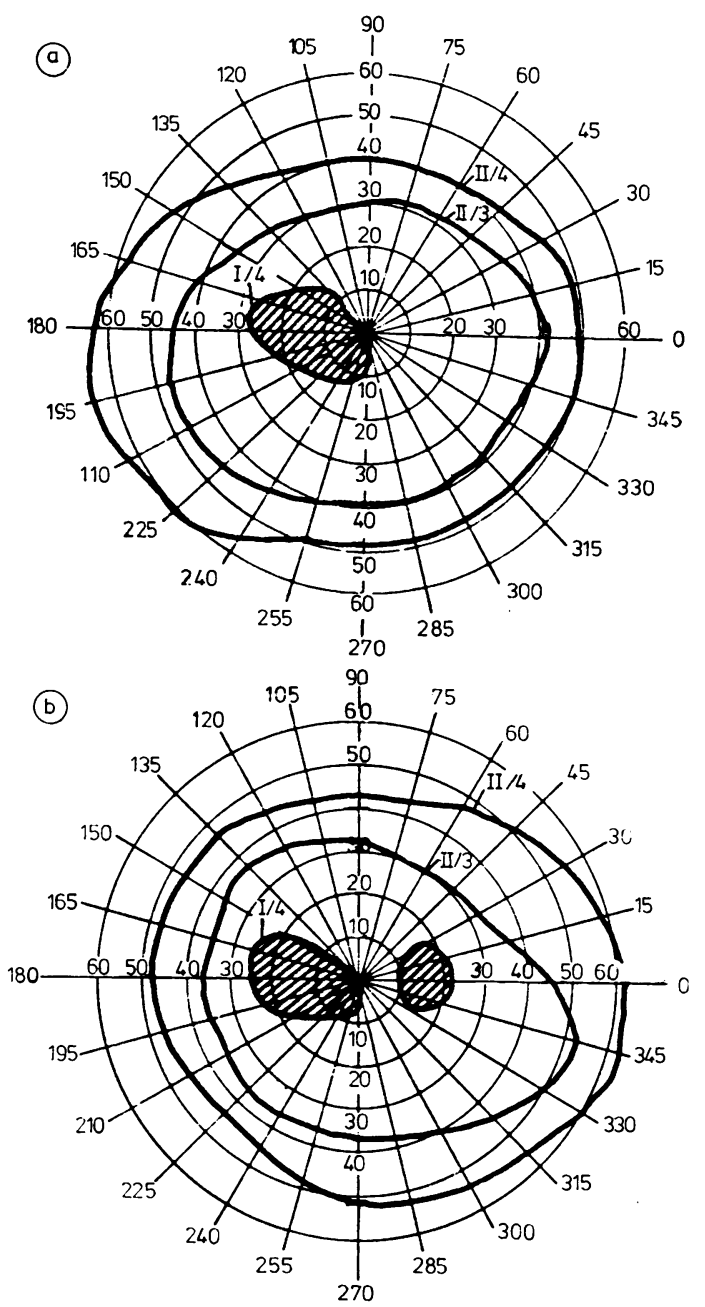

Fig 1 Visual field (a) left eye, (b) right eye. The homonymous visual field defect on the left includes the blind spot. The roman numerals mark the area of the test spot $\left(I=1 / 4 \mathrm{~mm}^{2} ; I I=1 \mathrm{~mm}^{2}\right)$, the arabic numerals the relative intensity $(3=0.315 ; 4=1 \cdot 00)$.

\section{Roentgenological findings}

Radiographs of the orbits and the sella turcica showed an excessive pneumatisation of the sphenoid sinus which extended to the base of the dorsum sella, from which it was only separated by a thin bony lamella.

\section{Isotope encephalographic findings}

After radionuclide examination had shown a discrete area of increased concentration of radioactivity in the 
occipital region which corresponded to the presumed area of infarction, CT was performed, and bilateral temporal lobe agenesis was found. No neurological abnormalities other than hemianopia were discovered at any time.

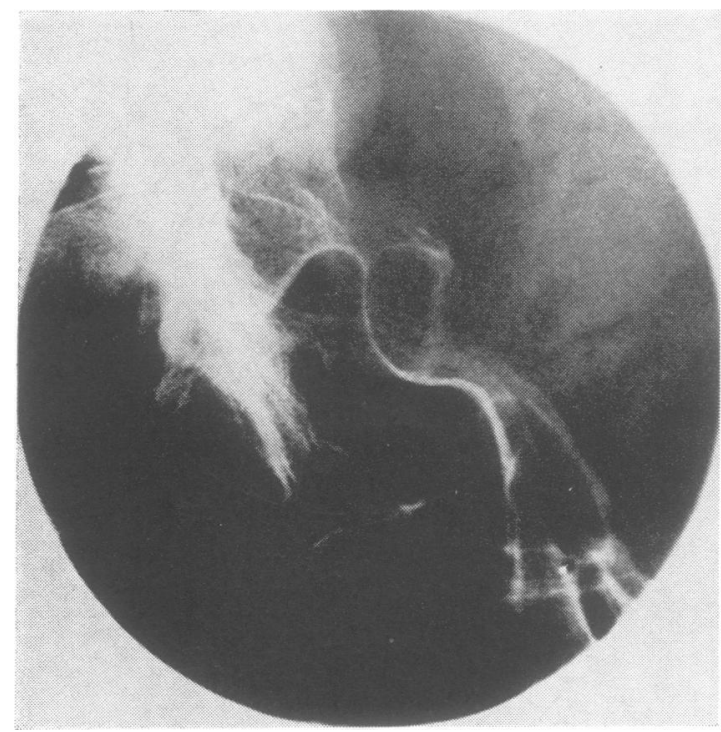

Fig 2 Plain radiographs show marked pneumatisation of the sphenoid sinus extending to the base of the dorsum sellae, from which it is separated only by a thin bony lamella.

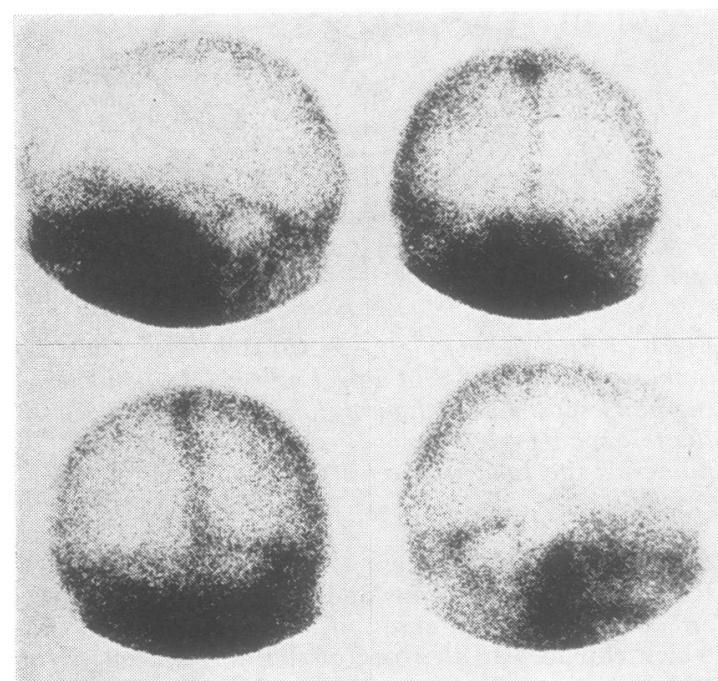

Fig 3 Static radionuclide scan with 99 m-Tcpertechnetate shows an occipital paramedian elevated concentration of radioactivity of the right side as a result of infarction.
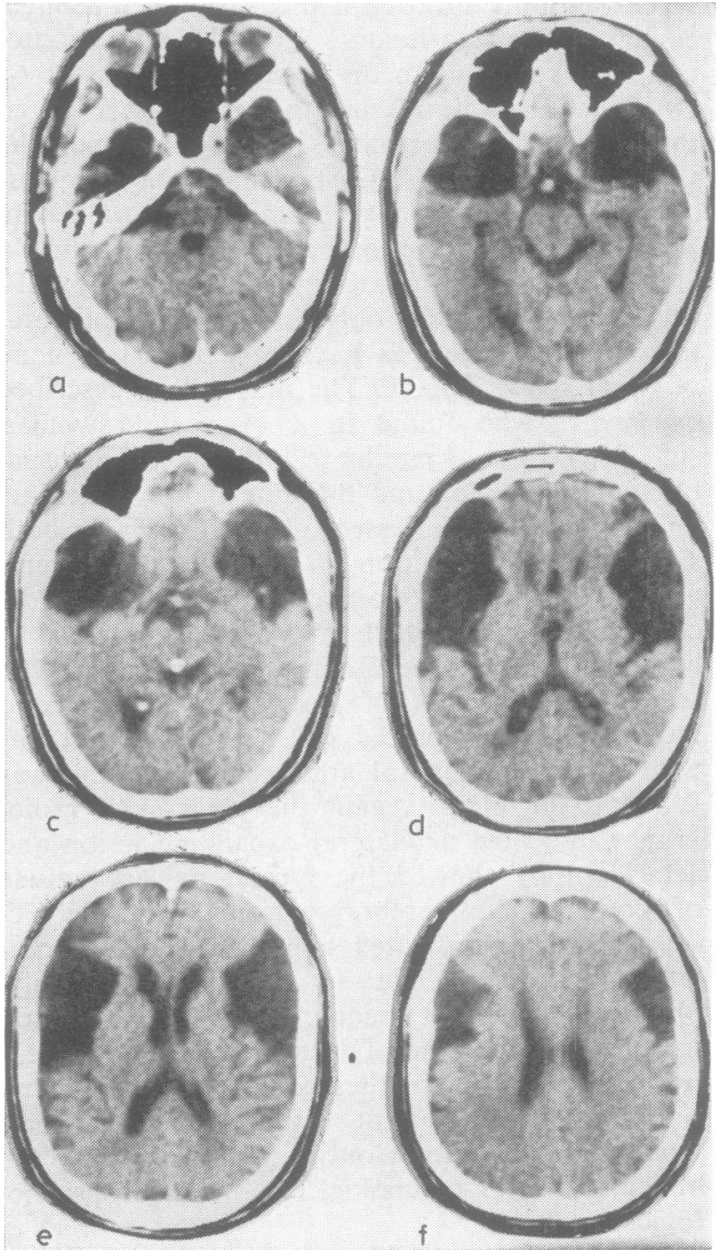

Fig $4(a-f)$ Bilateral temporal defects of a slightly higher density than CSF are shown. The temporal poles on both sides are missing, on the right side a small rim of temporal tissue can be seen. The cisterna pontis and cisterna laminae quadrigeminae are slightly enlarged as is the fourth ventricle.

\section{Psychological findings}

During and even at the end of the interviews the patient was calm, friendly, fresh and enterprising. He took part in the first four-hour-examination willingly without asking for pauses although he had had a one hour journey to the clinic driving his own car. He answered questions frankly, was spontaneous and talkative. The IQ as measured by the HAWIE (Wechsler-Adult-Intelligence-scale, German version) ${ }^{13}$ was 129 points, verbal and performance IQ were about the same. The relatively low score on the picturearrangement-subtest could be explained by the visual field defect. The IQ level was corroborated then by the MWT (Multiple-Choice-Vocabulary-Test by 
Lehrl), ${ }^{14}$ scoring 130 points. The non-verbal Raven progressive matrices, ${ }^{15}$ too, were clearly above average with a percentage of over 90 . The "Biographisches Inventar zur Diagnostik von Verhaltensstörungen" ("Biographical Inventory for the Diagnosis of Behavioural Disturbances") ${ }^{16}$ was answered in a way which showed marked ego-strength, mental as well as physical robustness and level-headedness, great social activity, extraversion, social openness, sociability and impulsiveness. High scores for mental stability on the neuroticism scale and medium scores on the extraversion scale in Eysenck's Personality Inventory (German version by Eggert) ${ }^{17}$ corresponded with these findings. The SKT (Syndrom-Kurz-Test) by Erzigkeit ${ }^{18}$ disclosed no impairment of attention, concentration and short-term-memory. The Defect Test by Kinzel, ${ }^{19}$ validated with regard to defect syndromes after cerebral contusion, revealed no difference from normal.

\section{Neuropsychological findings}

The Benton visual retention test ${ }^{20}$ gave hints of an organic cerebral defect; this however was most likely solely a consequence of the visual field defect. The difference between the number of correctly as well as incorrectly reproduced figures and the results expected was abnormal. Mistakes by rotation were the most frequent; furthermore distortions, one omission and one misplacing were noted. The patient stated that he was forced to move his head to and fro during the examination in order to discover all the relevant details. The testing for amusia was carried out by means of the Seashore-Test for Musical Abilities (German version by Butsch and Fischer). ${ }^{21}$ The scores were-as compared with a sample of normal 19-yearolds-average or above average. This excluded the presence of such a disturbance, as could be expected from the excellent musical skills already mentioned. The clinical impression of totally undisturbed linguistic abilities was confirmed by faultless performance in aphasia screening tests, the Token-Test by De Renzi and Vignolo (German version by Orgass) ${ }^{22} 23$ and the "Drei-Figuren-Test" (Three-Figures-Test) by Peuser. ${ }^{24}$ At no time was there an indication of prosopagnosia: the patient recognised without hesitation all examiners even after a period of six months.

\section{Discussion}

Classical clinico-neuropathological correlation implicitly suggests in a reductionistic way that mental functions consist of a number of relatively independent, elementary functions that are bound to circumscribed cerebral areas, so-called centres. Typical consequences of this concept are models such as the well-known Lichtheim-Wernicke aphasia schedule, and Henschen's ${ }^{25}$ or Kleist's ${ }^{26}$ cerebral maps where the abilities of acoustic attentiveness, melody, word, sentence and name recognition, noise, sound and tone perception are allocated to the temporal lobe. More recent concepts, however, emphasise the importance of a lesion's dynamics; mental abilities are not innate in certain cerebral areas, but are acquired during lifetime. Cases have been reported showing lesions of the dominant hemisphere without signs of aphasia or amusia. No symptoms of a KlüverBucy syndrome nor of prosopagnosia or memory deficit could be detected in our case as would have been expected if the lesions had developed rapidly during adult life. Karvounis, Chiu, Parsa and Gilbert ${ }^{4}$ emphasised the psychological normality of their 48-year-old patient, including clear consciousness, intact speech and undisturbed memory, although he was lacking the left temporal lobe. Tuynman, Hekster and Pauwels ${ }^{11}$ stressed the normal physical and intellectual development of their young patient with bilateral temporal lobe agenesis, while the psychiatric symptoms of Faris's ${ }^{10}$ patient apparently were not related to her cerebral lesion.

The malformation in our patient may be an example of Robinson's syndrome, in view of the temporal bulging, pneumatisation of the sphenoid sinus and the CT findings, although a genetic defect as the underlying disorder also must be considered. Temporal lobe agenesis is very rare and bilateral temporal lobe agenesis even rarer. A review of 650 patients by Paxton and Ambrose ${ }^{27}$ contains no example, nor does a survey of CT findings in cranio-cerebral anomalies by HarwoodNash. ${ }^{28}$ In a review of 5000 human brains, Shaw and Alvord ${ }^{12}$ discovered one example of bilateral temporal arachnoid cysts. Since almost all of these malformations were found incidentally only an increase in CT examinations is likely to disclose their true rate of occurrence.

\section{References}

1 Robinson RG. The temporal lobe agenesis syndrome. Brain 1964; 88:87-106.

2 Robinson RG. Agenesis and anomalies of other brain structures. In: Vinken PJ, Bruyn GW, eds. Handbook of Clinical Neurology, Vol 30, Congenital malformations of the brain and skull, Part I. Amsterdam: North Holland Publishing Co, 1977.

3 Seur NH, Kooman A. Arachnoid cyst of the middle fossa with paradoxical changes of the bony structures. Neuroradiology 1976; 12:17783.

4 Karvounis PC, Chiu JC, Parsa K, Gilbert S. Agenesis of temporal lobe and arachnoid cyst. NY State J Med 1970; 2349-53.

5 Aguilera F, Blázques MG, Obrador S. Quistes 
aracnoideos silvianos (Agenesia del lóbulo temporal). Rev Esp Otoneurooftalmol Neurocir 1970; 28:187-97.

6 Kolberg T. Die inscisurale Porencephalie des Temporallappens und das "temporal lobe agenesis syndrome". Neurochirurgia (Stuttg) 1978; 21: · 14-20.

7 Shields RA, Isherwood FFR, Pullan BR. The use of an off-line static display system with a computerized transverse axial tomographic unit. $\mathrm{Br}$ J Radiol 1974; 47:893-5.

8 New PFJ, Scott WR. Computed Tomography of the Brain and Orbit. Williams and Wilkins: Baltimore 1975.

9 Lange S, Grumme T, Meese W. Zerebrale Computer-Tomographie. Berlin: Schering AG 1977.

10 Faris MDM. Bitemporal bulging and thinning of the skull. Va Med 1966; 93:80-3.

11 Tuynman FHB, Hekster REM, Pauwels EKJ. Intracranial arachnoid cyst of the middle fossa demonstrated by positive $99 \mathrm{~m}$ Tc brainscintigraphy. Neuroradiology 1974; 7:41-4.

12 Shaw CM, Alvord EC jr. Congenital arachnoid cysts. In: Vinken PJ, Bruyn GW, eds. Handbook of Clinical Neurology Vol 31, Congenital malformations of the brain and the skull, Part II. Amsterdam: North Holland Publishing Co, 1977.

13 Wechsler D. Die Messung der Intelligenz Erwachsener. Huber, Bern 1956.

14 Lehrl S. Manual zum Mehrfachwahl-Wortschatztest MWT-B. Erlangen: Perimed 1977.

15 Raven JC. Guide to the Standard Progressive Matrices. London 1960.
16 Jäger R, Lischer S, Münster B, Ritz B. Biographisches Inventar zur Diagnose von Verhaltensstörungen (BIV). Göttingen: Hogrefe 1976.

17 Eggert D. Eysenck-Persönlichkeits-Inventar (EPI). Göttingen: Hogrefe 1974.

18 Erzigkeit H. Manual zum Syndrom-Kurztest (SKT). Vless, Vaterstetten 1977.

19 Kinzel W. Der Defektsyndrom-Test, Erfassung bleibender posttraumatischer Wesensänderungen. Ärztliche Praxis 1978; 30:491-4.

20 Benton AL, Spreen O. Handbuch zum BentonTest. Bern: Huber 1972.

21 Butsch C, Fischer H. Seashore-Test für musikalische Begabung. Bern: Huber 1966.

22 Orgass B. Eine revision des token tests. Diagnostica 1976; 22:70-87.

23 Orgass B. Eine revision des token tests. Diagnostica 1976; 22:141-56.

24 Peuser G. Der "Drei-Figuren-Test": ein neues Verfahren zur qualitativen und quantitativen Bestimmung von Sprachverständnisstörungen. In: Peuser G, ed. Interdisziplinäre Aspekte der Aphasieforschung. Köln 1976.

25 Henschen SE. Über Sprach-, Musik- und Rechenmechanismen und ihre Lokalisationen im Grosshirn. Z Gesamte Neurol Psychiatrie 1919; 52: 273-98.

26 Kleist K. Gehirnpathologie. Leipzig: Bart 1934.

27 Paxton R, Ambrose J. The EMI scanner: a brief review of the first 650 patients. Br J Radiol 1974; 47:530-65.

28 Harwood-Nash DC. Congenital craniocerebral abnormalities and computed tomography. Semin Roentgenol 1977; 12:39-51. 